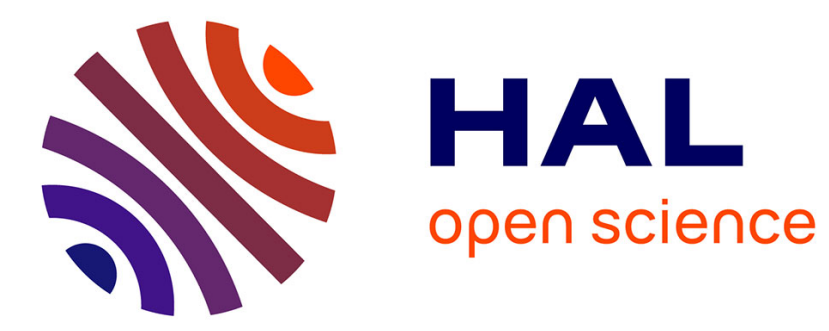

\title{
Generalised signalling: a possible solution to the paradox of language
}

Jean-Louis Dessalles

\section{To cite this version:}

Jean-Louis Dessalles. Generalised signalling: a possible solution to the paradox of language. The evolution of language, 2006, Singapore, Italy. pp.75-82. hal-00614808

\section{HAL Id: hal-00614808 \\ https://hal.science/hal-00614808}

Submitted on 21 Aug 2011

HAL is a multi-disciplinary open access archive for the deposit and dissemination of scientific research documents, whether they are published or not. The documents may come from teaching and research institutions in France or abroad, or from public or private research centers.
L'archive ouverte pluridisciplinaire HAL, est destinée au dépôt et à la diffusion de documents scientifiques de niveau recherche, publiés ou non, émanant des établissements d'enseignement et de recherche français ou étrangers, des laboratoires publics ou privés. 
Dessalles, J-L. (2006). "Generalised signalling: a possible solution to the paradox of language". In: A. Cangelosi, A. D. M. Smith \& K. Smith (Eds), The evolution of language. Singapore: World Scientific, 75-82.

\title{
GENERALISED SIGNALLING: A POSSIBLE SOLUTION TO THE PARADOX OF LANGUAGE
}

\author{
JEAN-LOUIS DESSALLES \\ ENST (ParisTech) \\ 46 rue Barrault - Paris, F-75013, France
}

\begin{abstract}
The systematic and universal communicative behaviour that drives human beings to give honest information to conspecifics during long-lasting conversational episodes still represents a Darwinian paradox. Attempts to solve it by comparing conversation with a mere reciprocal cooperative information exchange is at odds with the reality of spontaneous language use. The Costly Signalling Theory has recently attracted attention as a tentative explanation of the evolutionary stability of language. Unfortunately, it makes the wrong prediction that only elite individuals would talk. I show that as far as social bonding is assortative in our species, generalised signalling through language becomes a viable strategy to attract allies.
\end{abstract}

\section{Introduction: coping with the evolutionary paradox}

Language is an idiosyncratic property of the human species. Though, since the reasons for its very existence have been for long considered beyond question, the only remaining issues concerning its origin are to find out when, where and how it emerged in our lineage. Even recently, some authors insisted on the "obvious" necessity of language.

“ It is possible to imagine a superintelligent species whose isolated members cleverly negotiated their environment without communicating with one another, but what a waste! There is a fantastic payoff in trading hard-won knowledge with kin and friends, and language is obviously a major means of doing so " (Pinker, 1994:367.)

“ The adaptive significance of human language is obvious. It pays to talk. Cooperation in hunting, making plans, coordinating activities, task sharing, social bonding, manipulation and deception all benefit from an increase in expressive power. ” (Nowak \& Komarova, 2001)

Unfortunately, there is no way to prove the existence of a general selection pressure towards language that only our lineage would have been responsive to. Moreover, no satisfactory explanation is currently available to account for the fact that individuals would find a selective advantage in giving away hard-won knowledge about their physical and social environment for free.

Traditional intuitions about evolution based on the species' welfare or on group selection have been dismissed for a long time (Williams, 1966), and even if attempts have been made to revive them as potentially sound (Sober \& Wilson, 1998), it remains highly unlikely that such mechanisms produce any selection pressure $^{\text {a }}$ (Williams, 1966:112). The only traditional alternative left to explain altruistic talking to unrelated conspecifics is reciprocal cooperation (Trivers, 1971; Axelrod \& Hamilton, 1981). The conditions for the stable existence of cooperation are well known (Dessalles, 1999): good benefit-to-cost ratio and good cheater detection. Spontaneous language is far from meeting those requirements. The informational content of most everyday chatter is unlikely to significantly change the hearers' life expectancy, and the cost of talking should not be underestimated, if only for the time devoted to it (Dunbar, 1998). But the second constraint is even more patently infringed. Cheating, in the case of language, means that the addressee takes the information given and does not give information in return, even with delay. At first sight, the dialogic nature of many conversations seems to support the cooperative view. A closer examination of spontaneous exchanges reveals

\footnotetext{
${ }^{a}$ Elementary calculus shows that behaviour in favour of the collective with no return for the individual may have a slight positive effect on the frequency of that behaviour, but this effect requires strong heterogeneity and low migration within the population; it is frequency-dependent and vanishes when the behaviour becomes predominant; it presupposes the absence of any alternative behaviour that would be selfish and profitable. Simulations show that the effect does not emerge from noise and that it disappears when individuals endure event small costs.
} 
a quite different picture. To avoid cheating, speakers should rely on good assessment and memory of who gave valuable information to whom. Such bookkeeping is compatible with conspiratorial whispering, not with open conversation. Observation of spontaneous exchanges reveals that speakers talk to more than two addressees on average (Dunbar, Duncan \& Nettle 1995). If reciprocation were the underlying mechanism of language, talkative behaviour would have been selected against. There are more loquacious individuals around who are in search of an audience than people withholding valuable information and waiting for being prompted by avid hearers. Moreover, cheating detection seems to be performed by hearers rather than by speakers, as the former systematically point to any inconsistencies they perceive in what they hear (Dessalles, 1998). Conversation is more like scientific communication, in which authors strive to make a point that will be critically appraised by their colleagues, rather than like communication among spies or speculators, where information is exchanged on a strictly reciprocal basis. ${ }^{\text {b }}$

\section{Costly signalling and human language}

A new paradigm to explain non-kin altruism recently emerged from the pioneering work of Amotz Zahavi (Zahavi \& Zahavi, 1997). Altruistic behaviour may be performed in the absence of any reciprocation as a way to gain prestige in the group. The main claim of the theory is that these conducts evolved to advertise some quality. Another aspect of the theory is that competition leads to costly performance, as the handicap of the cost makes the performance a reliable indicator of the corresponding quality.

“ [...] my suggestion that altruism is an investment in advertisement by the individual altruist (that is, a handicap) shows how altruism can provide a direct benefit to the altruist. The individuals that accord prestige to the altruist do so not to encourage altruism, [... they] benefit directly from the information advertised by the altruistic act in their own decision making. " (Zahavi, 2003)

This model has been shown to be theoretically consistent (Grafen, 1990; Gintis, Smith \& Bowles, 2001). As stated in Zahavi's quotation, one crucial requirement is that the individuals that witness the performance benefit from making a good appraisal and reward good performers. The two sides of this requirement may be simultaneously fulfilled if the former make an asymmetrical alliance with the latter, e.g. becoming their disciples or conversely accepting them as coalition mates. In Gintis et al. model (2001), performers benefit from being chosen and discerning coalition partners benefit from choosing high quality performers.

We may say of those models that they are political, as they deal with fruitful alliances among individuals. The main reason for individuals to engage into coalition formation is that other individuals do so, what may create contexts in which isolated individuals are almost certain to lose. The crucial task each individual has to perform is to choose the best available allies, judging from available clues. As the individuals' true qualities are not directly observable, the selection task must rely on signals displayed by performers, as long as those signals are reliable. What Gintis et al. (2001) showed is that conditions do exist in which honest signalling is stable and provides a true indication of the individuals' quality. Though, realistic conditions that meet the model's requirements are still to be discovered.

Transposing Costly Signalling Theory (CST) to human language is not straightforward. Talking would be a way of advertising some crucial quality for forming efficient coalitions. Several problems must be solved: (1) Which quality is advertised through linguistic performance? (2) Is that quality positively correlated with the success of coalitions? (3) How is the reliability of signals enforced? (4) Why is language a generalised behaviour, while CST predicts that only high quality individuals should show off?

In previous work, we attempted to answer problems (1)-(3) (Dessalles 1998, 2000a, 2000b). (1) By striving to make relevant utterances, individuals would demonstrate their ability to extract information from their physical and social environment. Spontaneous conversations constitute an arena in which individuals compete to show that they were first to detect unexpected events that, without them, may have passed

\footnotetext{
${ }^{\text {b }}$ Cooperation can be made more robust by introducing intense punishment, but punishment exerted by speakers is absent from spontaneous language. Correlations between players are also known to stabilise cooperation, but they amount to introducing some dose of kin selection into the system. Human language is spontaneously used without specific and obligatory consideration of genetic, spatial or aspect closeness.
} 
unnoticed. (2) This informational ability is supposed to be a useful quality for large coalitions. When five coalition mates or more are to take coordinated action, the presence among them of individuals who are fully in touch with the physical and social environment is a crucial asset. Conversely, the coalition is unlikely to perform well if none of its members knows about what is going on around. Through language, individuals continuously demonstrate their ability to extract relevant information from their surroundings or from their past experience. Even if the recounted events are most often futile, it is still a good way to show off as a valuable coalition mate. (3) In CST, reliability is guaranteed by the cost of the performance. However, as Zahavi observes (Zahavi \& Zahavi 1997:223), it is easy to lie with words. If performance is appraised according to the informational unexpectedness or importance of the reported events, it is tempting to report highly unlikely events by merely inventing incredible situations and pretending to have witnessed them. We proposed that logic and argumentation evolved as a way to deter liars (Dessalles 1998), and that language may be honest in the absence of direct cost, as it is difficult to lie while remaining logically consistent.

Problem (4) remains a difficulty. In CST, signalling is honest as far as it allows telling apart high quality from low quality individuals. In an open and reliable competition, low quality individuals have no interest in showing off, as their performance would precisely reveal that their quality is low. How can we explain that language is a generalised behaviour in our species? CST would let us expect that only individuals capable of announcing big scoops or of making the soundest discussions would dare to talk. This is obviously not the case.

\section{The problem of the signalling threshold}

CST predicts a sharp cut-off in the level of signalling. Above a definite quality value, signalling becomes profitable, even if it is costly and altruistic, as the "political" return in terms of making efficient alliances compensates for the cost. Below that quality threshold, the probability of being chosen as coalition mate becomes too low and no longer compensates for the immediate cost. In previous unpublished attempts, we tried to circumvent the difficulty by adding noise and uncertainty both in the production of signals and in the formation of alliances. Though the consequence was an actual lowering of the signalling threshold, these efforts proved unsatisfactory. When signals become less correlated with the quality in demand, "customers" turn away from them even if communication is honest (Izquierdo et al., 2005). Moreover, as CST shows, good quality signallers evolve to reveal their higher quality anyway, most often by enduring high costs that lower quality individuals cannot afford.

In the case of language, even if logical testing by listeners can ensure reliability in the absence of significant marginal cost, the signalling threshold problem remains intact: we would expect that the only individuals talking in conversation would be those who were able to gather genuine extraordinary or crucial experience, while it would be advantageous for those who have only banal events to report to remain silent. Human verbal interactions would look be quite different from what they are, something like alarm calls that occur infrequently. ${ }^{\mathrm{c}}$

The thesis of this paper is that the existence of language, as it is practised hours each day by virtually all healthy individuals in traditional societies (Dunbar, 1998), can be explained within the CST framework under the assumption that social bonding is assortative.

\section{Language and assortative social bonding}

One crucial characteristic of human social behaviour is that it produces assortative matching. Even if you cannot become acquainted with prominent individuals many would dream of (for some it may be a famous actor, a politician, an important scientist or that person next door who ignores you), you still find some interest, and presumably some biological advantage, in establishing friendship bonds with people more like

\footnotetext{
c In some forms of signalling, the threshold may be close to zero, as is possibly the case for costly sexual mating in some singing bird species. If this is the case, it is due to the fact that males have no alternative than song to have the slightest chance for mating. This situation does not obtain in human coalition formation, as a variety of qualities such as fidelity, courage, efficiency or actual social status offer alternatives to informational abilities for showing off.
} 
you. The point is that assortative matching gives a chance to everyone to be chosen, and so everyone benefits from displaying her/his quality.

The crucial parameter is the difference between the maximal number of links coming to a node and the maximal number of links going out of a node in the graph of social bonds. If the former is much higher, as when many people admire an opera singer, the competition generates an elite. Don't attempt to sing opera in public if you have a faint voice. Human friendship functions differently. The maximal number of friendship bonds an individual is able to establish corresponds roughly to the number of different friendship bonds individuals would accept. A consequence is that, at equilibrium, friendship bonds are assortative, i.e. they bind individuals of comparable "quality" (for whatever relevant quality considered). Fig. 1 shows how pairings may stabilize to be roughly assortative during a computer simulation, as individuals of various qualities (on the horizontal axis, below) tend to bind with individuals of comparable quality (on the horizontal axis, above). The left part of the figure was obtained by imposing one-to-one pairings. The right part of the figure shows a case of non-assortative pairing.
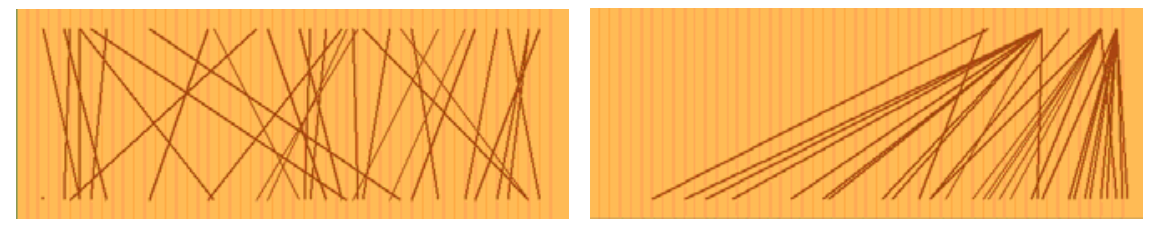

Figure 1. Examples of assortative (left) and non-assortative (right) pairings.

The political advantage for an agent of attracting allies may be written $f(q+\alpha Q)$, where $q$ is the quality of the individual, $Q$ the quality of the support provided by its allies, $\alpha$ is a constant and $f()$ an increasing function. In this simple model, individuals may reveal their quality by emitting a signal $s=g q$ that depends on their quality and on a genetically coded value $g$. Producing the signal involves the cost $C g$, where $C$ is a constant. Finally, the quality of the recruited allies, and thus their support, depends on $s: Q=h(s)$, where $h()$ is an increasing function. The benefit for the signalling individual is: $f(q+\alpha h(g q))-C g$. At equilibrium, its first derivative in $g$ is zero, and thus: $\alpha q h^{\prime}(g q) f^{\prime}(q+\alpha h(g q))=C$, which gives the optimal value of $g$ to which evolution will lead. $h^{\prime}(s)$ represents the marginal increase of the recruitment level. In the case of nonassortative paring, $h^{\prime}()$ is zero or negligible below a threshold value of the signal, where it takes high values. As a consequence, if $f()$ does not change value abruptly, the equation has no solution in $g$ for small values of $q$ and non-negligible cost $C$. This is the standard result of CST. In assortative pairing, $h()$ is expected to increase smoothly, as slightly better signals attract slightly better friends. $h^{\prime}(s)$ is thus non-zero and the equation may have a solution for any value of $q$, which means that signalling is now generalised.

Computer simulations confirm this result. Plots on Fig. 2 show how much individuals invest in communication, depending on their quality: low (black), medium low (white), medium high (red) and high (blue). The two first plots (left and middle) were obtained for two different benefit functions $f($ ). The plot in the middle shows that there are conditions in which, though communication remains honest, it is more profitable for low quality individuals to invest more in communication than higher quality individuals. The plot on the right corresponds to non-assortative links. It shows a typical CST result where only high quality individual are signalling.
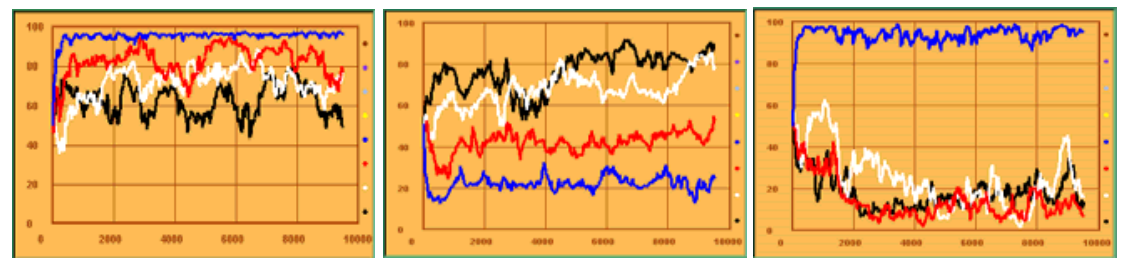

Figure 2. Three examples of evolution of investment in communication depending on quality. 


\section{Conclusion}

The main point of this paper was to show that generalised signalling is possible within the framework of CST thanks to assortative social bonding, and that the existence of language could be a consequence of this phenomenon. The crucial difference with various forms of kin-based cooperation, in which individuals are bound to interact with resembling or proximal partners, is that coalition mates choose each other. The fundamental hypothesis is that language controls social bonds, while actual bonds are not a prerequisite for the former to exist.

Several points must be more precisely investigated. For instance, several aspects of the social game, such as the selection of best partners by displaying individuals, are merely enforced in the simulation, instead of being left to emerge. We think nevertheless that this simple experimental setting offers new support to the idea that human language emerged as a signalling device to advertise information abilities.

\section{References}

Axelrod, R. \& Hamilton W. D. (1981). "The evolution of cooperation". Science 211, 1390-1396.

Dessalles, J-L. (1998). "Altruism, status, and the origin of relevance". In: J. R. Hurford, M. Studdert-Kennedy \& C. Knight (Eds), Approaches to the evolution of language: social and cognitive bases. Cambridge: Cambridge University Press, 130-147.

Dessalles, J-L. (1999). "Coalition factor in the evolution of non-kin altruism". Advances in Complex Systems 2(2), 143-172.

Dessalles, J-L. (2000a). Aux origines du langage : Une histoire naturelle de la parole. Paris: Hermèssciences.

Dessalles, J-L. (2000b). "Language and hominid politics". In: C. Knight, M. Studdert-Kennedy \& J. R. Hurford (Eds), The evolutionary emergence of language: social function and the origins of linguistic form. Cambridge: Cambridge University Press, 62-79.

Dunbar, R. I. M., Duncan N. \& Nettle D. (1995). "Size and structure of freely forming conversational groups". Human nature 6(1), 67-78.

Dunbar, R. I. M. (1998). "Theory of mind and the evolution of language". In: J. R. Hurford, M. StuddertKennedy \& C. Knight (Eds), Approaches to the evolution of language: social and cognitive bases. Cambridge: Cambridge University Press, 92-110.

Gintis, H., Smith E. A. \& Bowles S. (2001). "Costly Signaling and Cooperation". Journal of Theoretical Biology 213, 103-119.

Grafen, A. (1990). "Biological signals as handicaps". Journal of Theoretical Biology 144, 517-546.

Izquierdo, S. S., Izquierdo L. R., Galán J. M. \& Hernández C. (2005). "Market failure caused by quality uncertainty". In: P. Mathieu, B. Beaufils \& O. Brandouy (Eds), Artificial Economics. Springer LNEMS 564, 203-213.

Nowak, M. A. \& Komarova N. L. (2001). "Towards an evolutionary theory of language". Trends in cognitive sciences 5(7), 288-295.

Pinker, S. (1994). The language instinct. New York: Harper Perennial, ed. 1995.

Sober, E. \& Wilson D. S. (1998). Unto Others. The Evolution and Psychology of Unselfish Behavior. Cambridge, MA: Harvard University Press.

Trivers, R. L. (1971). "The evolution of reciprocal altruism". The Quaterly Review of Biology 46, 35-57.

Williams, G. C. (1966). Adaptation and natural selection: A critique of some current evolutionary thought. Princeton University Press, ed. 1996.

Zahavi, A. \& Zahavi A. (1997). The handicap principle. New York: Oxford University Press.

Zahavi, A. (2003). "Indirect selection and individual selection in sociobiology". Animal behaviour. 65, 859863. 